\title{
Social incentives for gender differences in the propensity to initiate negotiations: Sometimes it does hurt to ask
}

\section{Citation}

Bowles, Hannah Riley, Babcock, Linda, and Lai, Lei. "Social Incentives for Gender Differences in the Propensity to Initiate Negotiations: Sometimes It Does Hurt to Ask." Organizational Behavior and Human Decision Processes 103, no. 1 (2007): 84-103.

\section{Permanent link}

http://nrs.harvard.edu/urn-3:HUL.InstRepos:38437278

\section{Terms of Use}

This article was downloaded from Harvard University's DASH repository, and is made available under the terms and conditions applicable to Open Access Policy Articles, as set forth at http:// nrs.harvard.edu/urn-3:HUL.InstRepos:dash.current.terms-of-use\#OAP

\section{Share Your Story}

The Harvard community has made this article openly available. Please share how this access benefits you. Submit a story. 
Social Incentives for Gender Differences in the Propensity to Initiate Negotiations Sometimes It Does Hurt to Ask

Hannah Riley Bowles

John F. Kennedy School of Government, Harvard University

79 JFK Street, Cambridge, MA 02138

tel: 617496 4717, fax: 617496 3337, email: hannah_bowles@harvard.edu

Linda Babcock and Lei Lai

H. John Heinz III School of Public Policy and Management

Carnegie Mellon University

(Forthcoming in the journal of Organizational Behavior and Human Decision Processes) 


\begin{abstract}
Four experiments show that gender differences in the propensity to initiate negotiations may be explained by differential treatment of men and women when they attempt to negotiate. In Experiments 1 and 2, participants evaluated written accounts of candidates who did or did not initiate negotiations for higher compensation. Evaluators penalized female candidates more than male candidates for initiating negotiations. In Experiment 3, participants evaluated videotapes of candidates who accepted compensation offers or initiated negotiations. Male evaluators penalized female candidates more than male candidates for initiating negotiations; female evaluators penalized all candidates for initiating negotiations. Perceptions of niceness and demandingness explained resistance to female negotiators. In Experiment 4, participants adopted the candidate's perspective and assessed whether to initiate negotiations in same scenario used in Experiment 3. With male evaluators, women were less inclined than men to negotiate, and nervousness explained this effect. There was no gender difference when evaluator was female.
\end{abstract}

Keywords: ask, compensation, gender differences, gender role, negotiation, prescriptive sex stereotypes, social outcomes, status 
Social Incentives for Gender Differences in the Propensity to Initiate Negotiations Sometimes It Does Hurt to Ask

"There is no form of human excellence before which we bow with profounder deference than that which appears in a delicate woman....and there is no deformity in human character from which we turn with deeper loathing than from a woman forgetful of her nature, and clamorous for the vocation and rights of men.” Albert T. Bledsoe (1856, p. 224) ${ }^{1}$

Research on corporate managers suggests that women are less likely than men to use negotiation in upward influence attempts (Lauterbach \& Weiner, 1996). Other studies of broader populations indicate that women are less likely than men, in general, to initiate negotiations (Babcock, Gelfand, Small, \& Stayn, 2006; Babcock \& Laschever, 2003). Women report greater anxiety than men about negotiating and are less likely than men to perceive situations as negotiable (Babcock et al., 2006).

Conventional wisdom (e.g., "it pays to ask" and "the squeaky wheel gets the grease”) suggests that, if women want the same resources and opportunities as men, then they should learn to seek out, rather than shy away from, opportunities to negotiate. For instance, one study of the job negotiations of graduating professional school students found that only $7 \%$ of female students attempted to negotiate their initial compensation offers as compared to $57 \%$ of men. Those who negotiated gained on average 7.4\% over their initial offers (Babcock \& Laschever, 2003). Even small differences in starting salaries can lead to substantial compensation gaps over time (Bowles, Babcock, \& McGinn, 2005; Gerhart \& Rynes, 1991). Women’s reluctance as 
compared to men to initiate negotiations may be an important and under-explored explanation for the asymmetric distribution of resources, such as compensation, within organizations.

So, why would women let such opportunities pass? Maybe women need more training and practice in negotiation to help them get over their nervous feelings and to learn how to act more like the men when opportunities to negotiate arise. But, what if women's relative hesitation about initiating negotiations has less to do with their negotiating ability than with the way they are treated when they attempt to negotiate? "Fix the women” solutions to gender issues often fail to take into consideration the gendered social context out of which gender differences in behavior emerge (Deaux \& Major, 1987; Ely \& Meyerson, 2000; Wade, 2001; Watson, 1994b).

Society rewards and reinforces different types of behavior for men and women (Eagly, 1987), and it is not always good advice for women to act more like men in order to claim the same resources and privileges. Research on feminine modesty, for instance, shows that women tend to present themselves more modestly than do men (Daubman, Heatherington, \& Ahn, 1992; Gould \& Slone, 1982; Heatherington, Daubman, Bates, \& Ahn, 1993), and that a modest selfpresentation style tends to undermine perceived competence, particularly as compared to those who self-promote in a stereotypically masculine way (Rudman, 1998). However, if women attempt to overcome this “deficiency” by behaving in a more masculine self-promoting manner, they are perceived as technically skilled but lacking in social competence. This lack of social competence then detracts from their perceived hireability (Rudman, 1998). Similarly, research on gender and leadership has found that female leaders who attempt to establish their authority in a traditionally masculine (e.g., authoritative or directive) manner are evaluated more harshly than their male peers (Eagly, Makhijani, \& Klonsky, 1992). Perhaps in response to this resistance, women have tended to develop a more participative leadership style, which is correspondent with 
prescriptive gender roles for women (Eagly \& Johnson, 1990) and more effective for them than traditionally male leadership styles (Eagly, Johannesen-Schmidt, \& van Engen, 2003; Eagly, Karau, \& Makhijani, 1995).

The current research explores the question of whether gender differences in the propensity to initiate negotiations may be explained by differential treatment of men and women when they attempt to negotiate. ${ }^{2}$ We examine whether women encounter more social resistance than do men when they attempt to negotiate for higher compensation and whether the gender of the evaluator moderates that resistance. We investigate further whether women are less inclined than men to initiate compensation negotiations under those circumstances in which they are more likely than men to encounter social resistance. In this way, we are able to illuminate how differential treatment of male and female negotiators may motivate gender differences in the propensity to initiate negotiations over resources, such as compensation.

We focus on compensation negotiations, specifically, because of their important economic implications and because they represent a domain in which gender differences in negotiated outcomes are well documented (Barron, 2003; Bowles et al., 2005; Brett \& Stroh, 1997; Gerhart \& Rynes, 1991; Stevens, Bavetta, \& Gist, 1993). Recent developments in the study of gender in negotiation have made clear that gender effects in negotiation are situational (Bowles et al., 2005; Kray, Galinsky, \& Thompson, 2002; Kray, Reb, Galinsky, \& Thompson, 2004; Kray, Thompson, \& Galinsky, 2001; Stuhlmacher \& Walters, 1999; Walters, Stuhlmacher, \& Meyer, 1998). By focusing narrowly on compensation negotiations, we intend from the outset to limit the potential for generalization of our results in terms of negotiating contexts. That is to say, we would not expect women to encounter more social resistance than men across all types of potential negotiating contexts, nor would we expect women always to be more reluctant than 
men to negotiate. However, by demonstrating that women are more reluctant than men to negotiate in a context in which they face a greater social cost from doing so, we aim to illuminate the broader phenomenon that gender differences in the propensity to initiate negotiations may be motivated by social incentives as opposed to individual differences.

\section{Initiation of Compensation Negotiations as a Status Violation}

Prescriptive sex stereotypes stem from men’s higher status as compared to women within society (Conway, Pizzamiglio, \& Mount, 1996; Eagly \& Steffen, 1984; Hoffman \& Hurst, 1990; Jackman, 1994; Meeker \& Weitzel-O'Neill, 1977; Ridgeway \& Bourg, 2004). Societies with more gender equity tend to espouse less sexist beliefs (Glick et al., 2000). Within the U.S., as the proportion of women in the workplace has grown and the gender segregation of occupations has declined, women have come to identify more with masculine personality traits (Spence \& Buckner, 2000; Twenge, 1997) and society has come to view women of today and tomorrow as more masculine than women of the past (Cejka \& Eagly, 1999; Diekman \& Eagly, 2000).

Nevertheless, women are still expected to fulfill prescriptions of feminine niceness (e.g., warmth, kindness, sensitivity to the needs of others), which are emblematic of their subordinate status and therefore not fully compatible with all aspects of the masculine personality type (Jackman, 1994; Prentice \& Carranza, 2002; Ridgeway, 2001a; Rudman \& Glick, 2001).

In a recent test of contemporary college students' responses to two classic gender identity scales (Bem Sex Role Inventory by Bem, 1974; Personality Attributes Questionnaire by Spence \& Helmreich, 1978), Spence and Buckner (2000) found that women identified more strongly than men with all of the feminine items, but that men identified more strongly than women with only $41 \%$ of the masculine items. The majority of masculine items with which both men and women identified tended to relate to being active, independent and expressing one's own beliefs, 
whereas the items with which men identified more strongly than women tended to relate to being forceful, competitive and in charge. Rudman and Glick (2001) have argued that Spence and Buckman’s findings reflect two distinct dimensions of the masculine stereotype: competence and dominance. The majority of masculine traits with which both men and women equally identify are consistent with the "competence” dimension of the masculine stereotype. The minority of items with which men identify more strongly than women represent the "dominance" dimension of the masculine stereotype. While both competence and dominance are associated with higher status group members (Berger, Webster, Ridgeway, \& Rosenholtz, 1986; Carli, LaFleur, \& Loeber, 1995), Rudman and Glick argue that the traits and behaviors associated with masculine “competence” present less of a contradiction with the prescriptive norms of feminine behavior than do the traits and behaviors associated with masculine “dominance.”

Warmth and competence is an attractive, non-threatening combination (Carli et al., 1995; Fiske, Cuddy, Glick, \& Xu, 2002). While a women who projects her competence in a purely stereotypically masculine manner runs a higher risk of social resistance than a similarly selfpresented man (Carli, 1990; Carli et al., 1995; Eagly et al., 1992; Rudman, 1998; Rudman \& Glick, 1999; Rudman \& Glick, 2001), women can effectively convey their competence and be as influential as men, if they soften their stereotypically masculine competence with feminine niceness (Carli et al., 1995; Meeker \& Weitzel-O'Neill, 1977; Ridgeway, 1982; Rudman \& Glick, 2001). For instance, research on social influence shows that women can have as much social influence as men, by ensuring that they appear friendly as well as task-oriented rather than purely task-oriented (Carli et al., 1995) or by communicating their concern for the collective rather than their personal self-interest (Ridgeway, 1982). By employing a complementary combination of masculine competence and feminine niceness, women can make substantive 
contributions within traditionally male domains without challenging the hierarchical structure of gender relations (Carli et al., 1995; Meeker \& Weitzel-O'Neill, 1977; Ridgeway, 1982).

However, whereas women may temper resistance to their displays of masculine competence by combining them with stereotypically feminine behaviors, the display of masculine dominance directly contradicts the deferential and relational character of the feminine gender role (Eagly, 1987). Displays of masculine dominance by women pose a direct challenge to the gender status hierarchy and therefore a greater social risk than displays of masculine competence (Rudman \& Glick, 2001).

The act of attempting to negotiate competitively for greater personal resources, such as compensation, calls for a type of dominative masculine behavior that presents two problems for women. First, it violates prescriptions of feminine niceness and that violation is likely to engender social resistance (Burgess \& Borgida, 1999; Prentice \& Carranza, 2002; Wade, 2001). Second, women's attempts to initiate negotiations over compensation, in particular, may be resisted for the substance of the claim as well as for the behavior inherent in the request. Men's relatively greater economic resources as compared to women's are a source of status for them within society (Ridgeway, 2001b; Weber, 1968), and the complementarity of masculine and feminine gender roles (i.e., men as providers and women as care-givers) justifies and reinforces the asymmetric distribution of resources, such as compensation, favoring men (Jackman, 1994; Jost \& Kay, 2005). As lower status group members making claims to the privileges of higher status group members, women are likely to appear inappropriately demanding if they attempt to negotiate for higher levels of compensation. 
Hypothesis 1. The social cost of initiating negotiations for higher compensation will be greater for women than for men.

Hypothesis 2a. Perceived lack of niceness will explain the social resistance to women who attempt to negotiate for higher compensation as compared to those who do not.

Hypothesis 2b. Perceived demandingness will explain the social resistance to women who attempt to negotiate for higher compensation as compared to those who do not.

Because women's initiation of negotiations for resources, such as compensation, represents the type of dominative masculine behavior that challenges the gender status hierarchy, the relative social risk for women (as compared to men) may be greater when attempting to negotiate with a man as opposed to a woman (Carli, 1990; Deaux \& Major, 1987; Ridgeway \& Berger, 1986). Gender differences in status are more salient in mixed-gender than in samegender interactions, and greatest when the man is in a higher status role than the woman (Berger, Fisek, Norman, \& Zelditch, 1977; Deaux \& Major, 1987). Therefore, within the context of a potential compensation negotiation, gender differences in status are likely to be most influential when the candidate is female and the evaluator is male.

Research on prescriptive sex stereotypes has produced mixed findings with regard to the influence of the gender of the perceiver. Some studies find that female evaluators penalize women for gender-role violations as much as male evaluators (Butler \& Geis, 1990; Heilman \& Chen, 2005; Heilman, Wallen, Fuchs, \& Tamkins, 2004) and sometimes even more (Rudman, 1998). This work suggests that prescriptive sex stereotypes are generally held and reinforced by 
both men and women (Heilman \& Chen, 2005). Other studies find that male evaluators are more resistant than female evaluators to women who adopt high-status behaviors in their in social influence attempts (Carli, 1990; Carli et al., 1995) or who assume counterstereotypic high-status roles (Eagly et al., 1992; Rudman \& Kilianski, 2000; Schein, 2001). These other studies and research on social dominance orientation (e.g., see Sidanius, Pratto, \& Bobo, 1994) suggest that men may be more resistant than women to violations that challenge the gender-status hierarchy.

From this broader literature, the current work draws inspiration most directly from the theory and research on gender, status and social influence, which suggest that women’s persuasiveness with male evaluators, in particular, is contingent on their ability to signal their subordinate status (e.g., through niceness, tentativeness and other orientation) as well as their competence (Carli, 1990; Carli et al., 1995; Meeker \& Weitzel-O'Neill, 1977). Following these results and the logic that gender-related status differences are likely to be most salient in compensation negotiations when women are asking for more personal resources from men, we propose that the gender of the evaluator may moderate the relative social cost for women (as compared to men) of attempting to negotiate for higher compensation.

Hypothesis 3. The relative social cost for women as compared to men of initiating negotiations for higher compensation will be greater with male than with female evaluators.

This first set of hypotheses reflects the evaluator's perspective, describing the proposed influence of the gender of the target and the gender of the perceiver on evaluations of the initiation of the compensation negotiations. If these hypotheses are correct, then job candidates should take these social costs into account when making decisions about whether to negotiate. 
The following second set of hypotheses reflects the candidate's perspective. We propose that gender differences in the propensity to initiate compensation negotiations will be greater under those circumstances in which men and women tend to face differential treatment when they attempt to negotiate.

Hypothesis 4. Women will be more reluctant than men to initiate compensation negotiations.

Hypothesis 5. Women's relative reluctance (as compared to men) to initiate compensation negotiations will be greater when the evaluator is a man as opposed to a woman.

Consistent with the expectation of greater social costs from initiating compensation negotiations, we hypothesize that nervous feelings and anticipated negative social consequences (backlash) will mediate gender differences in the propensity to initiate negotiations.

Hypothesis 6a. Nervousness about attempting to negotiate will explain gender differences in the propensity to initiate compensation negotiations.

Hypothesis 6b. Anticipated backlash will explain gender differences in the propensity to initiate compensation negotiations.

In sum, as illustrated vividly by the opening quote, if women are perceived to be “clamoring” for the same resources as men, they may lose the grace of their idealized feminine niceness and be rejected for demanding that which is not due to them. We argue that gender 
differences in the social costs of attempting to negotiate for resources, such as compensation, may help to explain gender differences in the propensity to initiate negotiations. In the following experiments, we examine the judgments that male and female evaluators make when men and women attempt to negotiate and the role of the gender of the evaluator in shaping the decision to negotiate.

\section{Overview of Experiments}

In Experiment 1, we conducted a preliminary test of the hypothesis that there would be a higher social cost for women than for men from initiating negotiations. We then conducted a complementary set of experiments that tested for gender effects on both the likelihood of social resistance to negotiation attempts and on the propensity to initiate negotiations. In Experiments 2 and 3, participants adopted the role of senior manager in a corporation and evaluated an internal candidate based upon a transcribed (Experiment 2) or a videotaped (Experiment 3) job placement interview. Across the negotiation conditions, the candidates either accepted their compensation offers without comment (no ask) or initiated negotiations (ask). In Experiment 4, we reversed the participants’ perspectives. Using the same interview scenario, participants adopted the role of the job candidate and evaluated whether to initiate negotiations. By coupling these two perspectives on the same situation, we were able to test whether gender differences in the propensity to initiate negotiations (Experiment 4) would reflect differential treatment (Experiments 2 and 3), suggesting a social motivation for gender differences in the initiation of negotiations.

\section{Experiment 1}

In Experiment 1, we conducted a preliminary test of Hypotheses 1 and 3 in a 2 (gender of candidate) $\times 2$ (initiate negotiations: no ask vs. ask) $\times 2$ (gender of evaluator) between-subjects design. Participants evaluated a job candidate based on a resume and interview notes. The 
interview notes indicated whether the candidate was male or female and whether (or not) the candidate had attempted to negotiate for extra compensation and job benefits.

\section{Method}

\section{Participants}

The participants were 119 North American university students (66 men, 53 women) recruited from various points on a university campus (e.g., flyers, dining halls) to participate in a Hiring Decision Study. The median age was 20 years $(M=20.27$, Min = 18, $M a x=27)$. Fiftyfour percent of the participants were White, twenty-six percent were Asian, thirteen percent were African American, five percent were Hispanic and two percent reported “Other.” Participants received \$5 for completing the survey.

\section{Procedure}

After obtaining the participants' consent to participate in the study, the experimenter distributed paper packets containing background information on the hiring decision, the candidate's resume, and a set of notes from an interview with the candidate. The background information instructed participants to adopt the role of a commercial bank manager hiring a college student for a summer internship and to review the resume and interview notes. The candidate's resume was identical across conditions. We gave the candidate a gender-neutral first name and then referred to the candidate in the interview notes as either a man or a woman and with gender-appropriate pronouns. Participants in the No Ask condition read interview notes indicating a positive evaluation of the candidate’s personal qualities and experience (e.g., “[he/she] could definitely hit the ground running”). Participants in the Ask condition read the same set of general interview notes, and one additional note indicating that the candidate had asked for more compensation and had inquired about other additional job benefits (i.e., gym 
membership, access to a notebook computer and metro-pass). The experimenter distributed the four versions of interview notes randomly among participants. Participants responded on a 1-7 scale $(1=$ not at all, 7 = extremely) to two questions about how likely they thought it was they or someone else at the bank would hire this person for a summer internship. After submitting their assessment of the candidate's hireability, the participants filled out an exit survey that contained demographic questions, manipulation checks, and a debriefing form.

\section{Results}

All of the participants correctly identified whether the candidate was male or female. For all studies we used analysis of variance (ANOVA) to test the effects of gender of candidate, the ask manipulation, and gender of evaluator on the dependent measure. We combined the two hireability measures into one mean composite dependent measure $(\alpha=.83)$. As shown in Table 1 , there was a significant main effect for ask $(F[1,111]=29.97, p<.001)$ and a significant interaction of Gender of Candidate $\times \operatorname{Ask}(F[1,111]=4.80, p=.03)$. None of the other effects were significant ( $p s>$.31). As indicated by the means in Table 2, while the ask manipulation had a significant negative effect on the hireability of both male and female candidates, the negative effect for women was more than twice as large as that for men. ${ }^{3}$

\section{Discussion}

The results of Experiment 1 supported our prediction that evaluators would penalize a female candidate more than a male candidate for initiating negotiations (Hypothesis 1). Contrary to Hypothesis 3, the degree of resistance to female relative to male candidates was the same for male and female evaluators. It is noteworthy that evaluators were less inclined, in general, to hire the candidate who initiated negotiations. This suggested that our ask manipulation may have been too strong, particularly for a candidate who had yet to receive a job offer. In Experiment 2, 
we adjusted the scenario to make the potential negotiator an internal job candidate who had already received an offer for a new position, so that negotiating for higher compensation would be generally acceptable practice (Pinkley \& Northcraft, 2000; Thompson, 2005). We also tested two alternative scripts for the initiation of negotiations that varied in terms of the strength of argumentation that the candidate used to make the case for higher compensation.

\section{Experiment 2}

In Experiment 2, we tested Hypotheses 1-3 in a 2 (gender of candidate) $\times 3$ (initiate negotiations: no ask vs. moderate ask vs. strong ask) $\times 2$ (gender of evaluator) between-subjects design. Participants evaluated a candidate based on a transcript of a job placement interview. We ran two versions of the ask manipulation in order to explore whether the manner in which the candidate initiated negotiations would moderate the predicted interaction effect of Gender of Candidate $\times$ Ask on the willingness to work with the candidate.

\section{Method}

\section{Participants}

The participants were 299 college-educated adults (152 men, 147 women) recruited by a market research firm to participate in an online survey. The median age was 37 years $(M=39.2$, Min = 21, Max =64). Ninety-one percent of the participants self-identified as White, three percent as Asian, two percent as Hispanic, one percent as African American/Black, and three percent as “Other.” The median work experience was 17 years $(M=18.30, \operatorname{Min}=0, \operatorname{Max}=50)$. Eighty percent were currently employed. Sixty-nine percent of the participants had management experience. Those with management experience reported an average of 9.7 years of management experience. In exchange for completing the survey, the participants received points redeemable for prizes from the market research firm. 


\section{Procedure}

Participants accessed the survey remotely by responding to an email from the market research firm and clicking on a link to the Evaluation Survey website. After indicating their consent to participate in the study, the website directed the participants to a page of Background Information with links to a transcript from a job placement interview and an Evaluation Survey. The Background Information instructed participants to imagine they were senior managers in a corporation, and informed them that their task was to evaluate an internal candidate for a management position in their department. The Background Information continued on to explain that the candidate was in the process of completing a management training program before being assigned to a more senior management position within the company and that the candidate (like all those offered management positions) had graduated from a top school and performed well in the training program. The participant (as senior manager) wanted people in the department who were good team players and who worked well with other people.

After reviewing the Background Information, the website randomly assigned participants to read one of six interview transcripts (2[candidate: male, female] $\times 3$ [ask: no, moderate, strong]). We gave the candidate a gender neutral first name, and manipulated the gender of the candidate by referring to the candidate as Mr. or Ms. and with gender-appropriate pronouns. The first two interview questions and responses were identical across conditions. The questions related to the candidate's management training and work experience, and the responses indicated that the candidate had enjoyed and learned a lot in the training program and had some management experience running a school newspaper in college (431 words). In order to signal that the candidate was a good team player and worked well with other people, the response to the second question included statements such as, "I built a really strong team of people working 
together” and "I learned...how to get people motivated to do a good job.” We embedded the ask manipulation in the candidate's response to the third question about whether they had received their salary and benefits offer. Appendix A contains the wording of the third question and the scripts for the no ask, moderate ask and strong ask conditions.

After reviewing the transcript, the participants clicked on a link to the Evaluation Survey. The first step of the Evaluation Survey contained a list of characteristics, which we used to create our potential mediators (i.e., perceived niceness and demandingness). To create a measure of feminine niceness, we used seven of the ten items from Rudman and Glick’s (1999) Social Skills Index (good listener, helpful, kind, likeable, sensitive to the needs of others, supportive, warm). We removed three (friendly, popular and sincere) that seemed more relevant to social skills in general than prescriptions of feminine niceness, and added four more stereotypically feminine characteristics (agreeable, cooperative, modest, nurturing). We included another set of twelve words associated with demandingness (arrogant, cocky, demanding, dominating, obnoxious, overbearing, overconfident, presumptuous, pushy, self-centered, ungrateful, unreasonable). Participants rated on a scale of 1-7 ( $1=$ not at all, 7 = perfectly $)$ how much each of the words characterized their impression of the candidate. Finally, to create our dependent measure of willingness to work with the candidate, participants rated how beneficial it would be for them to have this person working for them, how much they would enjoy having this person working for them, and how likely it was that they would hire this person ( $1=$ not at all, $7=$ extremely).

After the participants submitted their responses to the Evaluation Survey, the website directed them to an exit survey that contained manipulation checks, demographic questions and debriefing materials. The manipulation checks tested whether the participants knew the gender of the candidate and how the candidate had responded to the third question (e.g., asked for high 
salary, asked for bonus). The debriefing materials included a question about what the participants thought the study was about while they were participating in it.

\section{Results}

We removed 63 cases because the participants failed to correctly identify the gender of candidate or whether the candidate asked for a higher salary. ${ }^{4}$ None of the participants reported that they suspected that it was a gender-related study. The sample of data analyzed included 236 participants (121 men, 115 women).

Dependent Measure: Willingness to Work with the Candidate

We combined the three measures of the evaluators' willingness to work with the candidate to create one mean composite dependent measure $(\alpha=.91)$. Preliminary analyses of the data showed that how the candidate attempted to negotiate for higher compensation (i.e., moderate ask vs. strong ask) had no significant effect on the influence of the gender of the candidate or the gender of the evaluator on the willingness to work with the candidate. In an ANOVA that restricted the analysis to the moderate ask and strong ask conditions, there was no significant interaction between of Gender of Candidate $\times$ Type of Ask $(F[1,150]=0.44, p=$ $.51)$, Gender of Evaluator $\times$ Type of Ask $(F[1,150]=2.10, p=.15)$, or Gender of Candidate $\times$ Gender of Evaluator $\times$ Type of Ask $(F[1,150]=0.21, p=.65)$. This indicates that the effects of gender of candidate and gender of evaluator on the willingness to work with the candidate did not differ by whether the ask manipulation was moderate or strong. Therefore, for the sake of parsimony, we collapsed the moderate ask and the strong ask conditions into one ask condition and presented our tests of the hypothesized interactions comparing the no ask condition to the combined ask condition. 
Table 3 displays the results of the ANOVA of the willingness to work with the candidate by gender of candidate, ask condition and gender of evaluator. We observed a significant main effect for ask $(F[1,228]=16.38, p<.001)$ and a significant interaction of Gender of Candidate $\times$ Ask $(F[1,228]=6.74, p<.02)$. None of the other effects were significant $(p s>.15)$. As can be seen from the means displayed in Table 4, attempting to negotiate for higher compensation had no significant effect on the evaluators' willingness to work with a male candidate, $t(116)=0.92$, $p=.92$. In contrast, attempting to negotiate significantly reduced the evaluators' willingness to work with a female candidate, $t(116)=4.72, p<.001$.

Potential Mediators: Niceness and Demandingness

We conducted a principal components factor analysis of the impression items with promax rotation. As anticipated, this analysis revealed two factors, which we combined into composite indicators of perceived niceness (eigenvalue $=11.41 ; \alpha=.92$ ) and perceived demandingness (eigenvalue $=2.18 ; \alpha=.95$ ). Table 5 displays means by condition for perceived niceness and demandingness. Niceness and demandingness were significantly correlated $r=-.66$, $p<.001$. The correlation between niceness and willingness to work was $r=.75(p<.001)$ and between demandingness and willingness to work was $r=-.57(p<.001)$. In a regression model of willingness to work on niceness and demandingness, each potential mediator had a significant, independent effect on the dependent variable $(\beta=.65, p<.001$ for niceness; $\beta=-.15, p<.02$ for demandingness; adjusted $\left.R^{2}=.56\right)$.

We used Sobel tests (Sobel, 1982) for all of our mediation analyses. ${ }^{5}$ As predicted, both niceness and demandingness fully mediated the negative effect of attempting to negotiate on the evaluators' willingness to work with a female candidate, Sobel $z=4.90, p<.001$ for niceness and Sobel $z=5.26, p<.001$ for demandingness. These variables, however, did not mediate the 
interaction effect of Gender of Candidate $\times$ Ask on willingness to work, Sobel $z=1.47, p=.14$ for niceness and Sobel $z=1.12, p=.26$ for demandingness.

\section{Discussion}

The results of Experiment 2 supported our hypothesis that women would incur a greater social cost from attempting to negotiate for higher compensation than would men (Hypothesis 1). Indeed, there was no significant decline in the evaluators' willingness to work with a male candidate who attempted to negotiate (vs. not). Women, in contrast, faced a large penalty-the negative effect of the ask manipulation was more than 5.5 times greater for women than for men. Interestingly, whether the candidate asked simply (moderate ask) or assertively (strong ask) had no effect on the relatively larger social cost for women as compared to men.

Mediation analyses further supported our hypotheses that social resistance to a female candidate who initiated negotiations would be explained by the evaluators' perceptions that she was not nice and overly demanding (Hypotheses 2a and 2b). It is noteworthy, however, that neither niceness nor demandingness mediated the interaction effect between the gender of the candidate and the ask manipulation. This suggests that, while perceived niceness and demandingness help to explain the evaluators' resistance to a woman who initiated compensation negotiations, they do not help to explain why there was a relative lack of resistance to the same behavior by a man.

Hypothesis 3 was not supported. There was no difference in the extent to which male and female evaluators penalized female relative to male candidates for initiating negotiations.

\section{Experiment 3}

In Experiment 3, we conducted another test of Hypotheses (1-3) in a 2 (gender of candidate) $\times 2$ (initiate negotiations: no ask vs. ask) $\times 2$ (gender of evaluator) between-subjects 
design. The scenario was identical to the one used in Experiment 2, except that the participants evaluated candidates based on their behavior in a videotaped interview. The videotaped candidates used the no ask and strong ask scripts that participants read in Experiment 2.

Our motivations for conducting the gender of candidate and ask manipulations with video rather than written scripts were multifold. Video broadens the bandwidth of communication relative to written transcripts by conveying additional nonverbal cues and, thereby, increases the social presence of the actor (Short, Williams, \& Christie, 1976; Walther \& Parks, 2002). Accordingly, we believed that the video would heighten the realism of the participants’ evaluation task and enhance the external validity of the results. While it is unusual to watch a videotape of a person's interview performance, it is even more out of the ordinary to review a transcript of their responses to interview questions. Interviewers generally benefit from hearing and seeing a candidate speak when making assessments about how much they would like to work with the person. Finally, Hypothesis 3 (regarding effects of the gender of the evaluator) was motivated in part by research on gender and social influence, which had employed videotapes (Carli et al., 1995). We anticipated that a richer communication medium might affect how the participants responded to the job candidates’ behavior (Walther \& Parks, 2002).

\section{Method}

\section{Participants}

The participants were 285 adults (107 men, 178 women). Participants signed up to complete a web-based survey called the Evaluation Study at one of two different websites that recruit experimental participants. Each of the websites lists studies that adults over 18 years of age may sign up to participate in for pay. The Evaluation Study was advertised as follows:

"Participants watch a short video of an interview and then answer a series of questions about the 
impression created by the interviewee.” Participants signed up to complete the study, and then the experimental laboratory sent them a link to the online survey that was valid for a limited time period of no longer than three days. There were no significant differences in the results obtained from the two sites, so we pooled the data. The median age was 29 years $(M=31.12, M i n=18$, Max $=62)$. Sixty-nine percent of the participants self-identified as White/Caucasian, twenty-four percent as Asian, three percent as Hispanic, two percent as African American/Black and two percent as Other (or no response). Thirty percent of the participants were currently students. Forty-four percent had no or some college, thirty-two percent were college graduates, and twenty-four percent had more than a college degree. The median work experience was seven years $(M=10.08, \operatorname{Min}=0, \operatorname{Max}=40)$. Forty-five percent of the participants had management experience. Those with management experience reported an average of 6.32 years of management experience. Participants received \$8 for completing the online survey. Procedure

The procedure was identical to that used in Experiment 2 except that the participants evaluated the candidate based on a videotape of their responses to the interview questions (as opposed to a transcript). The website randomly assigned participants to watch one of eight videos, so that each participant saw a head-and-shoulders shot of one of four candidates (two male, two female) who either accepted their compensation offer without comment or attempted to negotiate for a higher salary and bonus (no ask vs. ask). Participants in the ask condition saw the same video as the participants in the no ask condition, plus the segment in which the candidate attempted to negotiate for higher compensation. After watching the video, participants clicked on a link to the Evaluation Survey, which contained the same items reported in Experiment 2. The survey also included three questions about how competent they perceived the 
candidate to be (i.e., how likely it was that the candidate had the communication skills and analytical ability to be an effective manager and how confident the evaluator was that the candidate would be an effective manager). We had conceptualized the initiation of compensation negotiations as a form of dominative masculine behavior that is distinct from demonstrations of masculine competence, so we thought we should test whether (contrary to our expectations) women’s perceived competence would mediate the effect of the ask manipulation.

Manipulation of Gender of Candidate. We recruited two male and two female actors and recorded them enacting both the ask and no ask scripts in order to avoid confounds between actor and condition. We recruited undergraduate actors so that all of the candidates would appear to be in the same age cohort and age appropriate for the scenario. We selected actors whom we perceived to be of average attractiveness and asked them to wear professional dress. During the rehearsal for the taping, we coached them to enact the script as similarly as possible to one another (e.g., by providing instruction on tone and pace of voice, etc.). The actors spoke for 2.3 minutes on average in the no ask condition and for 3.5 minutes on average in the ask condition. The male (as compared to female) actors took four seconds more on average to complete the no ask script and ten seconds more on average to complete the ask script.

\section{Results of Video Rating}

While the videos enriched and enhanced the realism of the ask manipulation, they provided less control than a pen-and-paper experiment. Although we coached the actors to enact the script as similarly as possible, we could not control for natural variation in the actors' appearance and nonverbal behavior. For instance, women tend to smile more often than men (Dovidio, Brown, Heltman, \& Ellyson, 1988; Hall \& Halberstadt, 1986; LaFrance, Hecht, \& Paluck, 2003). If the female actors’ behavior differed more between the no ask and ask 
conditions than did the male actors' behavior (e.g., they smiled relatively less), then that would suggest an alternative explanation for any findings of interaction effects between the gender of the candidate and the ask manipulation.

One-hundred and ninety-six participants (93 men, 103 women) rated the actors (Mdn age =21). The online video-rating survey randomly assigned participants to watch one of the eight experimental videos with the sound turned off, so that the substance of the script would not bias their perceptions of the actor. Participants rated the candidates' appearance in terms of their age $(1=20-24,2$ = 25-29, 3 = 30-34, 4 = 35-39), socio-economic status $(1=$ low class, 2 = middle class, 3 = upper class $)$ and physical attractiveness (1-7 scale: $1=$ not at all, $7=$ extremely). They rated on a 1-7 scale ( $1=$ not at all, 7 = perfectly) how well the following adjectives characterized the actors' facial expressions: angry, happy, friendly, frowning, smiling and scowling. We used the participants’ ratings of the actors' facial expressions to create composite indicators of friendly expressions (happy, friendly, smiling; $\alpha=$.88) and angry expressions (angry, frowning, scowling; $\alpha=.80$ ). We used ANOVA for the 1-7 scale variables and ordered Logit regression for the other categorical variables to test whether the ask manipulation, the gender of the candidate, or the gender of the evaluator influenced raters' perceptions of the appearance and nonverbal behavior of the candidates.

There were no significant two-way or three-way interaction effects among the gender of candidate, gender of evaluator, and the ask conditions on the raters’ perceptions of the appearance or nonverbal behavior of the candidates ( $p s>.13)$. There were two main effects on the raters' perceptions of the candidates' appearance and non-verbal behavior. Raters perceived the female candidates to be more physically attractive than the male candidates $(F[1,188]=$ 27.08, $p<.001$, female $M=3.97, S D=1.12$, male $M=3.18, S D=1.12$ ) and to make more 
friendly expressions $(F[1,188]=13.86, p<.001$, female $M=4.22, S D=1.27$, male $M=3.47$, $S D=1.27)$. Although the female candidates came across as more attractive and friendly than the male candidates, these impressions, importantly, did not differ across the ask conditions.

\section{Results of Candidate Evaluation}

We now turn to the analysis of the participants’ willingness to work with the candidates. All of the participants correctly identified the gender of the candidate, and none of the participants reported that they suspected that it was a gender-related study. We removed 38 cases because the participants failed to correctly identify how the candidate had responded to the third question. ${ }^{6}$ The data analyzed contained 247 cases (95 men, 152 women).

Dependent Measure: Willingness to Work with the Candidate

As in Experiment 2, we combined the three measures of the evaluators' willingness to work with the candidate to create one composite dependent measure $(\alpha=.91)$. Table 6 displays the results of the ANOVA of willingness to work with the candidates by gender of candidate, ask condition, and gender of evaluator. We observed a significant main effect for ask $(F[1,239]=$ 34.71, $p<.001$ ) and a significant three-way interaction of Gender of Candidate $\times$ Ask $\times$ Gender of Evaluator $(F[1,239]=5.81, p<.02)$. No other effects were significant $(p s>.11)^{7}$

For the purpose of interpreting the three-way interaction, we conducted separate ANOVAs for female candidates and male candidates. The ANOVA of the willingness to work with female candidates by ask condition and gender of evaluator revealed a significant main effect for the ask manipulation $\left(F[1,120]=20.69, p<.001, \eta^{2}=.15\right)$ and no significant effects by gender of evaluator $\left(F s<1.35, p s>.24, \eta^{2}<.02\right)$. As indicated by the means in Table 7 , both male and female evaluators were less inclined to work with female candidates who initiated negotiations as compared to those who did not, $t(74)=2.61, p<.02$ for female evaluators and 
$t(46)=3.94, p<.001$ for male evaluators. ANOVA of the willingness to work with male candidates showed a significant main effect for the ask manipulation $(F[1,119]=14.21, p<$ $\left..001, \eta^{2}=.11\right)$ and a significant interaction effect of Ask $\times$ Gender of Evaluator $(F[1,119]=$ 5.27, $\left.p=.02, \eta^{2}=.04\right)$. There was no significant main effect of gender of evaluator, $F(1,119)=$ $\left.0.36, p=.55, \eta^{2}<.01\right)$. As shown by the means in Table 7 , attempting to negotiate for higher compensation had no significant effect on male evaluators' willingness to work with male candidates, $t(45)=0.90, p=.37$. However, the ask manipulation had a significantly negative effect on female evaluators' willingness to work with male candidates, $t(74)=5.06, p<.001$.

Another way of interpreting the three-way interaction is to split the ANOVA by gender of evaluator. For the ANOVA for female evaluators, there was a significant main effect for the ask manipulation $\left(F[1,148]=27.82, p<.001, \eta^{2}=.16\right)$ and no significant main or interaction effects by gender of candidate $\left(F s<2.24, p s>.13, \eta^{2}<.02\right)$. This indicates that male and female candidates incurred the same social cost for initiating negotiations with female evaluators. With male evaluators, there was a significant main effect for the ask manipulation $(F[1,91]=11.38, p$ $=.001, \eta^{2}=.11$ ), which was qualified by a significant interaction effect of Gender of Candidate $\times$ Ask $\left(F[1,91]=4.27, p=.04, \eta^{2}=.05\right)$, and no significant main effect of gender of candidate $\left(F[1,91]=0.71, p=.40, \eta^{2}<.01\right)$. As shown by the means in Table 7 , with male evaluators, female candidates incurred a significant social cost for initiating negotiations, whereas male candidates did not.

\section{Potential Mediators: Niceness, Demandingness and Competence}

We replicated the principal components factor analysis reported in Experiment 2. We combined the first factor (eigenvalue $=12.32$ ) into a composite indicator of perceived niceness $(\alpha=.94)$ and the second factor (eigenvalue $=2.93$ ) into a composite indicator of perceived 
demandingness $(\alpha=.96)$. We combined the three measures of how competent the evaluators perceived the candidates to be into one composite indicator of perceived competence $(\alpha=.87)$.

Table 8 displays means by condition for perceived niceness, demandingness and competence. Niceness and demandingness were significantly correlated $r=-.62, p<.001$. Evaluators perceived nicer candidates to be more competent $(r=.61, p<.001)$ and more demanding candidates to be less competent $(r=-.37, p<.001)$. Evaluators were significantly more inclined to work with candidates they perceived to be nice $(r=.79, p<.001)$ and competent $(r=.74, p<.001)$, and significantly less inclined to work with candidates they perceived to be demanding ( $r=-.63, p<.001$ ). In a regression model of willingness to work on niceness, demandingness, and competence, each potential mediator had a significant, independent effect on the dependent variable $(\beta=.39, p<.001$ for niceness; $\beta=-.23, p<.001$ for demandingness; $\beta=.41, p<.001$ for competence; adjusted $R^{2}=.76$ ).

Consistent with Hypotheses 2a and 2b, both perceived niceness and perceived demandingness fully mediated the effect of the ask manipulation on the evaluators' willingness to work with female candidates, Sobel $z=5.03, p<.001$ for niceness and Sobel $z=5.46, p<$ .001 for demandingness. The ask manipulation had no effect on the perceived competence of female candidates $(p>.20)$, so it was not a potential mediator. Post hoc analyses showed that perceived niceness, demandingness and competence mediated the interaction effect of Ask $\times$ Gender of Evaluator on the willingness to work with male candidates (Sobel $z=2.94, p<.01$ for niceness, Sobel $z=2.01, p=.04$ for demandingness, Sobel $z=2.03, p=.04$ for competence), explaining why female evaluators penalized male candidates for asking but male evaluators did not. None of the potential mediators explained the three-way interaction of Gender of Target $x$ Ask $\times$ Gender of Evaluator on the willingness to work with the candidates (Sobel test $p s>.12$ ). 


\section{Discussion}

The results of Experiment 3 supported Hypothesis 3: women paid a higher social cost for initiating compensation negotiations than men, but only with male evaluators. Attempting to negotiate for higher compensation had no effect on men's willingness to work with men, but it had a significantly negative effect on men's willingness to work with women. Women penalized men and women equally for attempting to negotiate.

The mediation analyses supported Hypotheses 2a and 2b. Even though the evaluators perceived the women who initiated compensation negotiations to be just as competent as those who did not, they were disinclined to work with them because they appeared less nice and more demanding. The mediation analyses did not explain why men evaluated male and female candidates differently, while women did not.

The effects of gender of evaluator in Experiment 3 follow a similar pattern to results observed in other video-based research on gender and social influence, in which female evaluators held men's and women’s influence attempts to a more similar standard than did male evaluators (Carli et al., 1995). However, these results contrast with those of Experiments 1 and 2, in which both male and female evaluators penalized women more than men for initiating negotiations. It is possible that the media richness of the video manipulation caused the women to perceive the male candidates’ negotiation attempts differently; when we presented the same behavior in a more socially distant, text format, the behavior did not seem so unattractive.

While there was some inconsistency in women's evaluations of men between the videobased and text-based experiments, men evaluated women more negatively than men for initiating negotiations across all three studies. This suggests that, while men may be as hesitant as women to initiate compensation negotiations with a female evaluator, women should clearly be more 
hesitant than men about initiating compensation negotiations with a male evaluator. In Experiment 4, we instructed participants to adopt the perspective of the candidate in the same scenario used in Experiments 2 and 3, in order to test whether gender differences in the propensity to initiate negotiate would reflect gender differences in the social risks of doing so.

\section{Experiment 4}

In Experiment 4, we tested our second set of hypotheses (4-6) in a 2 (gender of participant) $\times 2$ (gender of evaluator) between-subjects experimental design. Adopting the perspective of the candidate in the job placement interview scenario, participants reviewed two potential strategies for how to respond to a question about their salary and benefits offer. The two strategies were identical to the no ask and ask scripts in Experiment 3. In order to test for effects by gender of evaluator, we manipulated whether the participants (as candidate) wanted to work for a man or a woman.

\section{Method}

\section{Participants}

The participants were 367 adults (184 men, 183 women) recruited from the website of a university-based experimental research laboratory to participate in an Interview Preparation Study. The study was advertised as follows: "Participants will review a job interview scenario and answer questions about how they would prepare for the interview. After evaluating the interview information, participants will answer two brief surveys about themselves.” The median age of the participants was 21 years $(M=23.92, \operatorname{Min}=18, \operatorname{Max}=64)$. Sixty percent of the participants self-identified as White/Caucasian, eighteen percent as Asian, ten percent as African American/Black, eight percent as Hispanic, and four percent as Other. Seventy-eight percent of 
the participants were full-time university students. The median work experience was four years $(M=5.72$, Min $=0, \operatorname{Max}=42)$. Participants received $\$ 15$ for participating in the study.

\section{Procedure}

After obtaining the participants’ consent to participate in the study, the experimenter distributed paper packets containing background information on the interview preparation scenario. The background material instructed participants to imagine that they had just completed a management training program in preparation for a more senior management position within their company. According to the background materials, the participants were about to participate in a placement interview to determine the department to which they would be assigned. Participation in the study involved preparing for that interview.

Ask vs. No Ask Plan. The background information presented participants with three questions that the interviewer was likely to ask, and provided prepared answers to the first two questions. (The answers to the first two questions were identical to the responses given by the candidates in Experiments 2 and 3.) The task for participants was to decide between two alternative answers (i.e., Plan A or Plan B) to the third question, which related to their salary and benefits offer from the company. Plan A was the no ask script used in Experiments 2 and 3, and Plan B was the strong ask script used in Experiment 2 and the ask script used in Experiment 3.

Gender of Evaluator. Consistent with Experiments 2 and 3, the background information informed the participants that the senior manager they really wanted to work for was known to hire people who are good team players and who work well with other people. In order to manipulate gender of evaluator, we gave the manager a gender neutral name, and then referred to the manager either as a man or as a woman and with corresponding male or female pronouns. 
Measures. After reviewing the background materials, the participants completed an online Interview Preparation Survey in which they assessed each of the plans. Participants rated each plan individually in terms of how they would feel about using the plan and whether they anticipated negative social consequences from using the plan. We used these ratings to create our potential mediators: nervousness and anticipated backlash. Participants rated on a scale of 1-7 (1 = disagree completely, 7 = agree completely) how embarrassed, comfortable, nervous, relaxed, and anxious they would feel using each of the plans. Participants answered two questions on a scale of 1-7 (1 = disagree completely, 7 = agree completely) about whether they thought a man (or woman) like [name of manager] would not want to hire or work with them if they used either plan. ${ }^{8}$ Finally, participants rated which plan they would be more likely to use relative to the other ( 1 = I would be much more likely to use [the no ask plan], 7 = I would be much more likely to use [the ask plan]). This was our dependent measure of the propensity to initiate negotiations.

Because our hypotheses derived from the basic proposition that gender differences in the propensity to initiate negotiations are motivated by differences in the social feedback that men and women receive when they attempt to negotiate, we thought we should explore the alternative hypothesis that gender differences in the propensity to initiate negotiations are a function of the negotiator's gender identity (i.e., the extent to which the negotiator identifies with masculine and feminine personality traits regardless of whether the negotiator is a man or a woman). After submitting their responses to the Interview Preparation Survey, the participants completed a second online Personality Profile Survey that included the 30 items from the Bem Sex-Role Inventory (BSRI) short form (Bem, 1981).

A final online exit survey contained manipulation checks, demographic questions and debriefing materials. The manipulation checks tested whether the participants knew the 
difference between Plans A and B and the gender of the evaluator. Debriefing materials included a question about what they thought the study was about while they were participating in it.

\section{Results}

We removed 18 cases because the participants failed to provide correct answers on the manipulation checks. We removed 8 cases because participants suspected the study was about gender in hiring or negotiation. ${ }^{9}$ The data analyzed contained 341 cases (171 men, 170 women). Dependent Variable: Use of Ask vs. No Ask Plan

The overall mean rating of the likelihood of using the ask vs. the no ask plan was significantly lower than the indifference point between the two options (4), indicating that participants tended to favor the no ask over the ask plan, $M=2.24, t(340)=18.79, p<.001$. As shown in Table 9, ANOVA revealed a significant interaction of Gender of Participant $\times$ Gender of Evaluator on the likelihood of using the ask vs. no ask plan $(F[1,337]=4.13, p=.04)$, but no main effects for gender of participant or gender of evaluator ( $p s>.28)$. As shown in Table 10, when the evaluator was male, women were significantly less inclined than men to use the ask vs. no ask plan, $t(159)=2.06, p=.04$. Consistent with the results of Experiment 3, when the evaluator was female, men were as likely as women to use the ask vs. no ask plan, $t(178)=-0.72$, $p=.47$.

\section{Potential Mediators: Nervousness, Anticipated Backlash, and Gender Identity}

Following Hypothesis 6, we tested whether nervousness and anticipated backlash would explain the gender difference in the propensity to initiate negotiations with a male evaluator.

Nervousness. We used the emotions variables to create a mean composite indicator of nervousness about using the ask plan $(\alpha=.87)$. Feeling nervous about using the ask plan was negatively correlated with the likelihood of using the ask vs. no ask plan $(r=-.57, p<.001)$. As 
shown in Table 11, women reported significantly more nervousness than men about using the ask plan when facing a male evaluator, $t(159)=2.78, p<.01, d=.43$. Nervousness about using the ask plan fully mediated the effect of gender of participant on the likelihood of using the ask vs. no ask plan with a male evaluator, Sobel $z=2.61, p<.01$. However, nervousness did not mediate the interaction of Gender of Candidate $\times$ Gender of Evaluator on the likelihood of using the ask vs. no ask plan (Sobel $z=1.07, p=.28$ ). This means that, while nervousness explained why there was a gender difference in the propensity to initiate negotiations with a male evaluator, it did not explain why the gender difference was greater with a male than with a female evaluator.

Anticipated Backlash. We combined the two items about whether using the ask plan would make the evaluator not want to hire or work with them into a mean composite indicator of anticipated backlash $(\alpha=.86)$. Anticipated backlash from using the ask plan was negatively correlated with the likelihood of using the ask vs. no ask plan $(r=-.55, p<.001)$. The more backlash the participants anticipated, the more nervous they felt about using the ask plan, $r=.51$, $p<.001$. However, as shown in Table 11, there was no significant difference by gender of participant in anticipated backlash from using the ask plan with a male evaluator, $t(159)=1.04, p$ $=.30, d=.16$. Anticipated backlash did not mediate the effect of gender of participant on the likelihood of using the ask plan with a male evaluator (Sobel $z=1.03, p=.30$ ), nor did it mediate the interaction between gender of participant and gender of candidate on the likelihood of using the ask plan (Sobel $z=1.77, p=.08$ )

Gender Identity. Finally, we examined whether identification with masculine and feminine traits would mediate or moderate gender effects on the propensity to initiate negotiations. There was no gender difference in the participants' identification with masculine 
personality traits, female $M=4.97, S D=.81$, male $M=5.05, S D=.84, t(339)=0.94, p=.35, d$ $=.10$. Female (vs. male) participants identified more strongly with feminine personality traits, female $M=5.55, S D=.79$, male $M=5.25, S D=.88, t(339)=3.33, p<.001, d=.36$. The participants’ masculinity and femininity scores were positively correlated, $r=.11, p=.04$. Identification with masculine traits was negatively correlated with nervousness $(r=-.15, p<$ $.01)$, uncorrelated with anticipated backlash $(r=-.03, p=.55)$, and positively correlated with use of the ask vs. no ask plan $(r=.14, p=.01)$. There was no significant correlation between the participants' femininity scores and nervousness, anticipated backlash or use of the ask vs. no ask plan $(r s<.04, p s>.54)$.

Given the potential for participants to identify strongly with one, both or neither of the scales (i.e., be masculine or feminine identified, androgynous or undifferentiated) (Bem, 1974), we used regression analysis to test whether the interaction of the masculinity and femininity scores was correlated with nervousness, anticipated backlash or use of the ask vs. no ask plan; we observed no significant effects ( $p s>.12$ ). Because there was no gender difference in the participants' masculinity scores and no other correlations with use of the ask vs. no ask plan, gender identity was not a candidate for mediation. Gender identity also had no significant moderating effect on the propensity to initiate negotiations; we observed no significant interaction effects between the BSRI scores and gender of participant $(p s>.09)$ or gender of evaluator ( $p s>.20)$ on the likelihood of using the ask vs. no ask plan.

\section{Discussion}

The female (as compared to male) participants in Experiment 4 were more reluctant to attempt to negotiate for higher compensation, but only when the evaluator was male. When the evaluator was female, women were as inclined as men to attempt to negotiate for higher 
compensation. Consistent with Hypothesis 5 and mirroring the results of Experiment 3, the gender of the evaluator was a significant moderator of the effect of gender of participant on the propensity to initiate compensation negotiations.

Mediation analysis showed that women (as compared to men) were significantly more reticent to initiate negotiations with a male evaluator because the prospect of doing so made them more significantly more nervous (Hypothesis 6a). Contrary to our predictions, anticipated backlash did not mediate gender differences in the propensity to initiate negotiations with a male evaluator (Hypothesis 6b). Neither nervousness nor anticipated backlash explained why the gender difference in the propensity to negotiate was greater with a male than with a female evaluator. The results of the mediation analyses suggest that women's greater hesitation (as compared to men) about attempting to negotiate for higher compensation may be informed more by emotional intuition than a conscious cost-benefit calculus based upon the anticipated social consequences of initiating negotiations. Future research should take advantage of developments in the study of emotions in decision making (Damasio, 1994) and explore the relative influence of emotions and conscious reasoning in the reinforcement of status-based behavioral norms.

Finally, we tested for possible mediating and moderating effects of gender identity on the propensity to initiate negotiations. The higher the participants' masculinity scores, the more likely they were to choose the negotiation option. However, gender identification did not explain gender differences in the propensity to initiate negotiations with a male evaluator. These results further support the proposition that gender effects on the propensity to initiate negotiations are motivated by differential treatment of men and women as opposed to personality differences. 


\section{General Discussion}

We posed the question at the beginning of this paper of whether women's greater reluctance (as compared to men) to initiate negotiations over resources, such as higher compensation, could be explained by the differential treatment of male and female negotiators. The results of these experiments suggest that the answer to this question is yes. In the first three experiments, male evaluators penalized women more than men for attempting to negotiate for higher compensation. In Experiment 4, women were more reticent than men about attempting to negotiate for higher compensation with a male evaluator, and nervousness about attempting to negotiate explained this gender difference. The results of the mediation analyses in Experiments 2 and 3 were consistent with the proposition that women encounter resistance when they attempt to negotiate for higher compensation because such behavior is a status violation. Men were significantly more inclined to work with nicer and less demanding women who accepted their compensation offers without comment than they were with those who attempted to negotiate for higher compensation, even though they perceived women who spoke up to be just as competent as women who demurred.

The behavior of female evaluators differed across Experiments 1, 2 and 3. When evaluating written descriptions or transcripts of the candidates' interview responses (Experiments 1 and 2), female evaluators penalized women more than men for attempting to negotiate for higher compensation. After watching and listening to the candidates respond to the interview questions on video (Experiment 3), female evaluators were disinclined to work with both men and women who initiated negotiations. Interestingly, the behavior of the participants in Experiment 4 mirrored most closely the results of the video-based experiment; there was no difference in men's and women's propensity to initiate negotiations with a female evaluator. 
Previous video-based research on gender and social influence produced a similar pattern of results to those reported in Experiment 3, with men demanding a higher degree of likeability from female than from male targets to be persuaded by them and women perceiving likeability to be important to the persuasiveness of both men and women (Carli et al., 1995). More theory and research are needed to explore more deeply the role of the gender of the evaluator in the reinforcement of prescriptive sex stereotypes and to disentangle the inconsistencies in the effect of the gender of the evaluator observed across these studies and in the broader literature on prescriptive sex stereotypes (Heilman \& Chen, 2005). The current set of studies suggests that future research on the effect of the gender of the evaluator should explore potential methodological as well as contextual moderators (Carli, 1990; Deaux \& LaFrance, 1998; Deaux \& Major, 1987; Kanter, 1977).

\section{Negotiation and the Distribution of Organizational Resources}

This research has important implications for the distribution of resources and opportunities within organizations. If men have more freedom to negotiate for themselves than do women, particularly with senior men, then that could help to explain phenomena, such as the gender wage gap and glass ceiling. In most organizations, those who control organizational resources and opportunities for advancement tend to be men. If women are justifiably less inclined than men to initiate negotiations with men, then they may have fewer opportunities to increase their compensation and promotion potential.

It is not clear from the results of these experiments that men consciously resist women's attempts to negotiate. The results of Experiment 4 indicated that women (as compared to men) were more reticent about negotiating with a male evaluator because the idea of doing so made them more nervous and not because they anticipated more backlash. It warrants further 
investigation whether men's resistance to women who initiate compensation negotiations is also motivated more by a feeling of aversion or discomfort than by a conscious decision that such behavior by women should be discouraged. Research on the challenges to women of breaking the glass ceiling, for instance, indicates many male CEOs think that women should take more initiative to signal their interest in critical developmental experiences (Ragins, Townsend, \& Mattis, 1998). Future research should explore whether raising awareness about the systemic reasons for gender differences in the initiation of negotiations might help to mitigate the social risks for women. Moreover, both male and female managers should keep in mind that negotiation is a fundamental form of social interaction within organizations, and a potentially important mechanism for the retention and attraction of talented labor (Rousseau, 2005). More research is needed to understand better the organizational implications of inhibiting the initiation of negotiations over issues such as compensation.

\section{The Decision to Negotiate}

Whether our participants' behavior was optimal, in terms of weighing the actual social and economic costs and benefits of initiating compensation negotiations, remains an open question. The benefits of initiating negotiations in this type of context would obviously include the expected compensation gains, and the costs would include the risks of undermining potentially important working relations and missing out on desirable work opportunities. If the expected economic gains were large enough to outweigh the social costs, then the rational course of action would be to initiate negotiations, in spite of the social costs. If the social costs and their long-term career implications outweighed the benefits of higher compensation, then reticence would be the more prudent choice. We cannot claim, based on our research, that either men or women are initiating negotiations too much or too little. We show with this research that 
women's disinclination relative to men to initiate negotiations over resources, such as compensation, may be traced to the higher social costs that they face when doing so.

It deserves highlighting that, on average, both men and women in Experiment 4 preferred the no-negotiation to the negotiation plan for responding to a question about their salary and benefits offer. This may be attributable in part to the artificiality of choosing between two predetermined scripts rather than choosing one’s own words to negotiate. However, research on the propensity to initiate negotiations reveals relatively low overall rates of initiation. For instance, studies of the salary negotiations of graduating professional school students suggest that less than a third of students initiate compensation negotiations (32\% in study by Babcock \& Laschever, 2003; 21\% in study by Gerhart \& Rynes, 1991). In recent laboratory research, only 12\% of participants initiated negotiations when they knew they might earn more if they asked (Babcock, Laschever, Gelfand, \& Small, 2003). These low baselines of negotiation raise important questions about the decision to negotiate that have yet to be addressed in the literature. Future research should investigate the motivations for this hesitancy, particularly in situations in which the economic costs to not negotiating are substantial.

\section{Limitations}

One limitation of our experimental design was the artificiality of the negotiation and nonegotiation scripts. If the candidates had been able to choose their own words, it is possible that men and women would have presented themselves differently (Barron, 2003). We weighed this limitation, however, against the benefits of enabling us to test the effects of gender of participant, gender of evaluator and gender identification on perceptions of a specific set of behavioral choices and to test in Experiments 2 and 3 how evaluators would perceive men and women enacting the precise behaviors that the participants assessed in Experiment 4. Future research 
should explore whether men and women initiate negotiations in different ways and whether variation in accounts (Scott \& Lyman, 1968) or self-presentation style (Carli, 1990; Carli et al., 1995) would moderate the evaluation of their negotiation attempts.

\section{Contributions}

Our findings reinforce the importance for negotiation scholars and practitioners of considering the social as well as economic outcomes of negotiation (Curhan, Elfenbein, \& Xu, in press; Morris, Larrick, \& Su, 1999). This work adds to this understudied area of research in negotiation by providing another demonstration that the social costs of engaging in certain negotiating behaviors may not outweigh the economic benefits (Morris et al., 1999). When focusing primarily on economic outcomes of negotiation, we fail to appreciate fully the costs and benefits of negotiation processes and their products.

The current research also contributes to the growing body of literature on gender in negotiation in at least four respects. First, whereas previous research has focused on internal motivations for gender differences in the propensity to initiate negotiations (Babcock et al., 2006), this set of studies demonstrates clearly that men and women face different social incentives when deciding whether to initiate negotiations over issues such as compensation. This advancement is important because it should shift the discussion of prescriptive implications away from fixing the women to addressing the social conditions that motivate these gender differences (Watson, 1994b). Second, by demonstrating that there are contextual explanations for gender effects in negotiation behavior, we contribute empirical research to a long line of theoretical work that has criticized the sex-difference approach to the study of gender in negotiation (Gray, 1994; Kolb \& Putnam, 1997; Kolb \& Williams, 2000; Wade, 2001; Watson, 1994a, 1994b). 
Third, this research adds to the recent body of work on sex stereotypes in negotiation by illuminating the influence of prescriptive, as opposed to descriptive, sex stereotypes (Burgess \& Borgida, 1999) - or, in terms of social role theory, stereotypes about gender roles as opposed to sex-typed skills (Eagly, 1987). Whereas previous research has demonstrated various ways in which gender-based performance expectations shape negotiation outcomes (Kray et al., 2002; Kray et al., 2004; Kray et al., 2001), this research shows that gender-based norms of appropriate behavior may influence whether individuals decide to negotiate and the social outcomes of their negotiations. Future research should continue this exploration of how gendered expectations of appropriate negotiating behavior may influence negotiation performance (Wade, 2001).

Fourth, this work contributes to the documentation of situational moderators of gender effects in negotiation. Contrary to the proposition that women are always more reluctant than men to negotiate, we found that women were only more reluctant than men to attempt to negotiate in the situation in which the relative social risk was greatest (i.e., with a male evaluator). Future research should draw motivation from developments in the study of situational moderators of gender effects in negotiation (Bowles et al., 2005; Kray \& Thompson, 2005; Walters et al., 1998) and continue to explore the boundaries of gender differences in the propensity to initiate negotiations. For instance, the activation of explicit sex stereotypes favoring men or of implicit sex stereotypes favoring women might prompt women to initiate negotiations more often than men (Kray et al., 2002; Kray et al., 2001). To the extent that men and women differ in relational orientation (Cross \& Madson, 1997; Gabriel \& Gardner, 1999), manipulation of the current or potential future relationship between negotiating parties might moderate gender effects in the propensity to initiate negotiations (Gelfand, Major, Raver, Nishii, \& O'Brien, 2006). Gender differences in the propensity to initiate negotiations might also be 
influenced by the prospective negotiator's representation role (i.e., for self vs. other). Previous research suggests that women are more motivated in compensation negotiations when they are representing someone else as opposed to themselves (Bowles et al., 2005).

Finally, these findings have important implications for the teaching and practice of negotiation, because they show that one-size-fits-all prescriptions may not turn out to be "best practice” for both male and female negotiators. This research suggests that gender differences in the initiation of negotiations cannot be resolved simply by encouraging women to speak up more. Addressing this issue requires an understanding of the situational circumstances that motivate gender differences in the propensity to initiate negotiations and a set of prescriptions that alter the behavior of evaluators as well as negotiators. 


\section{References}

Aroian, L. A. (1947). The probability function of the product of two normally distributed variables. Annals of Mathematical Statistics, 18, 265-271.

Babcock, L., Gelfand, M., Small, D., \& Stayn, H. (2006). Gender differences in the propensity to initiate negotiations. In D. D. Crèmer, M. Zeelenberg \& J. K. Murnighan (Eds.), Social Psychology and Economics (pp. 239-259). Mahwah, NJ: Lawrence Erlbaum.

Babcock, L., \& Laschever, S. (2003). Women don't ask. Princeton, NJ: Princeton University Press.

Babcock, L., Laschever, S., Gelfand, M., \& Small, D. (2003). Nice girls don't ask. Harvard Business Review, 81, 14-15.

Barron, L. (2003). Ask and you shall receive? Gender differences in beliefs about requests for a higher salary. Human Relations, 56, 635-663.

Bem, S. L. (1974). The measurement of psychological androgyny. Journal of Consulting and Clinical Psychology, 42, 155-162.

Bem, S. L. (1981). Bem Sex-Role Inventory. San Francisco, CA: Consulting Psychology Press.

Berger, J., Fisek, M. H., Norman, R. Z., \& Zelditch, M. E. (1977). Status characteristics and social interaction: An expectation-states approach. New York: Elsevier.

Berger, J., Webster, M., Jr., Ridgeway, C. L., \& Rosenholtz, S. J. (1986). Status cues, expectations and behaviors. In E. Lawler (Ed.), Advances in group processes (Vol. 3, pp. 1-22). Greenwich, CT: JAI Press.

Bledsoe, A. T. (1856). An essay on liberty and slavery. Philadelphia: J. B. Lippincott. 
Bowles, H. R., Babcock, L., \& McGinn, K. L. (2005). Constraints and triggers: Situational mechanics of gender in negotiation. Journal of Personality and Social Psychology, 89, 951-965.

Brett, J. M., \& Stroh, L. K. (1997). Jumping ship: Who benefits from an external labor market career strategy? Journal of Applied Psychology, 82, 331-341.

Burgess, D., \& Borgida, E. (1999). Who women are, who women should be: Descriptive and prescriptive gender stereotyping in sex discrimination. Psychology, Public Policy, and Law, 5, 665-692.

Butler, D., \& Geis, F. L. (1990). Nonverbal affect responses to male and female leaders: Implications for leadership evaluations. Journal of Personality and Social Psychology, 58, 48-59.

Carli, L. L. (1990). Gender, language, and influence. Journal of Personality and Social Psychology, 59, 941-951.

Carli, L. L., LaFleur, S. J., \& Loeber, C. C. (1995). Nonverbal behavior, gender, and influence. Journal of Personality and Social Psychology, 68, 1030-1041.

Cejka, M. A., \& Eagly, A. H. (1999). Gender-stereotypic images of occupations correspond to the sex segregation of employment. Personality and Social Psychology Bulletin, 25, 413423.

Conway, M., Pizzamiglio, M. T., \& Mount, L. (1996). Status, communality, and agency: Implications for stereotypes of gender and other groups. Journal of Personality and Social Psychology, 71, 25-38.

Cross, S. E., \& Madson, L. (1997). Models of the self: Self-construals and gender. Psychological Bulletin, 122, 5-37. 
Curhan, J. R., Elfenbein, H. A., \& Xu, A. (2006). What do people care about when they negotiate? Mapping the domain of subjective value in negotiation. Journal of Personality and Social Psychology, 91, 493-512.

Damasio, A. R. (1994). Descartes' error: Emotion, reason, and the human brain. New York: G.P. Putnam.

Daubman, K. A., Heatherington, L., \& Ahn, A. (1992). Gender and the self-presentation of academic achievement. Sex Roles, 27(3-4), 187-204.

Deaux, K., \& LaFrance, M. (1998). Gender. In D. T. Gilbert, S. Fiske \& G. Lindsey (Eds.), The handbook of social psychology (4th ed., pp. 788-827). Boston: McGraw-Hill.

Deaux, K., \& Major, B. (1987). Putting gender into context: An interactive model of genderrelated behavior. Psychological Review, 94, 369-389.

Diekman, A. B., \& Eagly, A. H. (2000). Stereotypes as dynamic constructs: Women and men of the past, present, and future. Personality and Social Psychology Bulletin, 26, 1171.

Dovidio, J. F., Brown, C. E., Heltman, K., \& Ellyson, S. L. (1988). Power displays between women and men in discussions of gender-linked tasks: A multichannel study. Journal of Personality and Social Psychology, 55, 580-587.

Eagly, A. H. (1987). Sex differences in social behavior: A social-role interpretation. Hillsdale, NJ: Erlbaum.

Eagly, A. H., Johannesen-Schmidt, M. C., \& van Engen, M. L. (2003). Transformational, transactional and laissez-faire leadership styles: A meta-analysis comparing men and women. Psychological Bulletin, 129, 569-591.

Eagly, A. H., \& Johnson, B. T. (1990). Gender and leadership style: A meta-analysis. Psychological Bulletin, 108, 233-256. 
Eagly, A. H., Karau, S. J., \& Makhijani, M. G. (1995). Gender and the effectiveness of leaders: A meta-analysis. Psychological Bulletin, 117, 125-145.

Eagly, A. H., Makhijani, M. G., \& Klonsky, B. G. (1992). Gender and the evaluation of leaders: A meta-analysis. Psychological Bulletin, 111, 3-22.

Eagly, A. H., \& Steffen, V. J. (1984). Gender stereotypes stem from the distribution of women and men into social roles. Journal of Personality and Social Psychology, 46, 735-754.

Ely, R. J., \& Meyerson, D. E. (2000). Theories of gender in organizations: A new approach to organizational analysis and change. Research in Organizational Behavior, 22, 103-151.

Fiske, S. T., Cuddy, A. J. C., Glick, P., \& Xu, J. (2002). A model of (often mixed) stereotype content: Competence and warmth respectively follow from perceived status and competition. Journal of Personality and Social Psychology, 82, 878-902.

Gabriel, S., \& Gardner, W. L. (1999). Are there 'his' and 'hers' types of interdependence? The implications of gender differences in collective versus relational interdependence for affect, behavior, and cognition. Journal of Personality and Social Psychology, 77, 642655.

Gelfand, M., Major, V. S., Raver, J., Nishii, L. H., \& O'Brien, K. (2006). Negotiating rationally: The dynamics of the relational self in negotiations. Academy of Management Review, 31, 427-451.

Gerhart, B., \& Rynes, S. (1991). Determinants and consequences of salary negotiations by male and female MBA graduates. Journal of Applied Psychology, 76, 256-262.

Glick, P., Fiske, S. T., Mladinic, A., Saiz, J. L., Abrams, D., Masser, B., et al. (2000). Beyond prejudice as simple antipathy: Hostile and benevolent sexism across cultures. Journal of Personality and Social Psychology, 79, 763-775. 
Goodman, L. A. (1960). On the exact variance of products. Journal of the American Statistical Association, 55, 708-713.

Gould, R. J., \& Slone, C. G. (1982). The "feminine modesty" effect: A self-presentational interpretation of sex differences in causal attribution. Personality and Social Psychology Bulletin, 8, 477-485.

Gray, B. (1994). The gender-based foundations of negotiation theory. In R. Lewicki, B. Sheppard, \& M. Bazerman (Eds.), Research on negotiations in organizations (Vol. 4, pp. 3-36).

Hall, J. A., \& Halberstadt, A. G. (1986). Smiling and gazing. In J. S. Hyde \& M. C. Inn (Eds.), The psychology of gender: Advances through meta-analysis. Baltimore, MD: John Hopkins University Press.

Heatherington, L., Daubman, K. A., Bates, C., \& Ahn, A. (1993). Two investigations of "female modesty" in achievement situations. Sex Roles, 29, 739-754.

Heilman, M. E., \& Chen, J. J. (2005). Same behavior, different consequences: Reactions to men's and women's altruistic citizenship behavior. Journal of Applied Psychology, 90, 431-441.

Heilman, M. E., Wallen, A. S., Fuchs, D., \& Tamkins, M. M. (2004). Penalties for success: Reactions to women who succeed at male gender-typed tasks. Journal of Applied Psychology, 89, 416-427.

Hoffman, C., \& Hurst, N. (1990). Gender stereotypes: Perception or rationalization? Journal of Personality and Social Psychology, 58, 197-208.

Jackman, M. R. (1994). The velvet glove: Paternalism and conflict in gender, class, and race relations. Berkeley, CA: University of California Press. 
Jost, J. T., \& Kay, A. C. (2005). Exposure to benevolent sexism and complementary gender stereotypes: Consequences for specific and diffuse forms of system justification. Journal of Personality and Social Psychology, 88, 498-509.

Kanter, R. M. (1977). Men and women of the corporation. New York: Basic Books.

Kolb, D. M., \& Putnam, L. L. (1997). Through the looking glass: Negotiation theory refracted through the lens of gender. In S. Gleason (Ed.), Frontiers in Dispute Resolution in Industrial Relations and Human Resources (pp. 231-257). East Lansing, MI: Michigan State University Press.

Kolb, D. M., \& Williams, J. (2000). The shadow negotiation: How women can master the hidden agendas that determine bargaining success. New York: Simon \& Schuster.

Kray, L. J., Galinsky, A., \& Thompson, L. (2002). Reversing the gender gap in negotiations: An exploration of stereotype regeneration. Organizational Behavior and Human Decision Processes, 87, 386-409.

Kray, L. J., Reb, J., Galinsky, A. D., \& Thompson, L. (2004). Stereotype reactance at the bargaining table: The effect of stereotype activation and power on claiming and creating value. Personality and Social Psychology Bulletin, 30, 399-411.

Kray, L. J., \& Thompson, L. (2005). Gender stereotypes and negotiation performance: A review of theory and research. In B. M. Staw \& R. Kramer (Eds.), Research in Organizational Behavior Series (Vol. 26, pp. 103-182). Greenwich, CT: JAI Press.

Kray, L. J., Thompson, L., \& Galinsky, A. (2001). Battle of the sexes: Gender stereotype confirmation and reactance in negotiations. Journal of Personality and Social Psychology, 80, 942-958. 
LaFrance, M., Hecht, M. A., \& Paluck, E. L. (2003). The contingent smile: A meta-analysis of sex difference in smiling. Psychological Bulletin, 129, 305-334.

Lauterbach, K. E., \& Weiner, B. J. (1996). Dynamics of upward influence. Leadership Quarterly, 7, 87-107.

Meeker, B. F., \& Weitzel-O'Neill, P. A. (1977). Sex roles and interpersonal behavior in taskoriented groups. American Sociological Review, 42, 91-105.

Morris, M. W., Larrick, R. P., \& Su, S. K. (1999). Misperceiving negotiation counterparts: When situationally determined bargaining behaviors are attributed to personality traits. Journal of Personality \& Social Psychology, 77, 52-67.

Myrdal, G. (1994). An American dilemma: The Negro problem and modern democracy. New York: Harper \& Brothers.

Pinkley, R. L., \& Northcraft, G. B. (2000). Get paid what you're worth: The expert negotiator's guide to salary and compensation. New York: St. Martin's Press.

Prentice, D. A., \& Carranza, E. (2002). What women and men should be, shouldn’t be, are allowed to be, and don’t have to be: The contents of prescriptive gender stereotypes. Psychology of Women Quarterly, 26, 269-281.

Ragins, B. R., Townsend, B., \& Mattis, M. (1998). Gender gap in the executive suite: CEOs and female executives report on breaking the glass ceiling. The Academy of Management Executive, 12, 28-42.

Ridgeway, C. L. (1982). Status in groups: The importance of motivation. American Sociological Review, 47, 76-88.

Ridgeway, C. L. (2001a). Gender, status, and leadership. Journal of Social Issues, 57, 637-655. 
Ridgeway, C. L. (2001b). How do status beliefs develop? The role of resources and interactional experiences. In J. Jost \& B. Major (Eds.), The psychology of legitimacy: Emerging perspectives on ideology, justice and intergroup relations (pp. 357-377). Cambridge, England: Cambridge University Press.

Ridgeway, C. L., \& Berger, J. (1986). Expectations, legitimation, and dominance behavior in task groups. American Sociological Review, 51, 603-617.

Ridgeway, C. L., \& Bourg, C. (2004). Gender as status: An expectation states theory approach. In A. H. Eagly, A. E. Beall \& R. J. Sternberg (Eds.), The psychology of gender (pp. 217241). New York: Guliford Press.

Rousseau, D. (2005). I-deals, idiosyncratic deals employees bargain for themselves. Armonk, NY: M. E. Sharpe.

Rudman, L. A. (1998). Self-promotion as a risk factor for women: The costs and benefits of counterstereotypical impression management. Journal of Personality and Social Psychology, 74, 629-645.

Rudman, L. A., \& Glick, P. (1999). Feminized management and backlash toward agentic women: The hidden costs to women of a kinder, gentler image of middle managers. Journal of Personality and Social Psychology, 77, 1004-1010.

Rudman, L. A., \& Glick, P. (2001). Prescriptive gender stereotypes and backlash toward agentic women. Journal of Social Issues, 57, 743-762.

Rudman, L. A., \& Kilianski, S. E. (2000). Implicit and explicit attitudes toward female authority. Personality and Social Psychology Bulletin, 26, 1315-1328.

Schein, V. E. (2001). A global look at psychological barriers to women's progress in management. Journal of Social Issues, 57, 675-688. 
Scott, M. B., \& Lyman, S. M. (1968). Accounts. American Sociological Review, 33, 46-62.

Short, J., Williams, E., \& Christie, B. (1976). The social psychology of telecommunications. New York: John Wiley \& Sons.

Sidanius, J., Pratto, F., \& Bobo, L. (1994). Social dominance orientation and the political psychology of gender: A case of invariance? Journal of Personality and Social Psychology, 67, 998-1011.

Sobel, M. E. (1982). Asymptotic intervals for indirect effects in structural equations models. In S. Leinhart (Ed.), Sociological methodology (pp. 290-312). San Francisco: Jossey-Bass.

Spence, J. T., \& Buckner, C. E. (2000). Instrumental and expressive traits, trait stereotypes, and sexist attitudes. Psychology of Women Quarterly, 24, 44-62.

Spence, J. T., \& Helmreich, R. L. (1978). Masculinity and femininity: Their psychological dimensions, correlates, and antecedents. Austin: University of Texas Press.

Stevens, C. K., Bavetta, A. G., \& Gist, M. E. (1993). Gender differences in the acquisition of salary negotiation skills: The role of goals, self-efficacy, and perceived control. Journal of Applied Psychology, 78, 723-735.

Stuhlmacher, A. F., \& Walters, A. E. (1999). Gender differences in negotiation outcome: A meta-analysis. Personnel Psychology, 52, 653-677.

Thompson, L. (2005). The mind and heart of the negotiator (3rd ed.). Upper Saddle River, N.J.: Prentice Hall.

Twenge, J. M. (1997). Changes in masculine and feminine traits over time: A meta-analysis. Sex Roles, 36, 305-325.

Wade, M. E. (2001). Women and salary negotiation: The costs of self-advocacy. Psychology of Women Quarterly, 25, 65-76. 
Walters, A. E., Stuhlmacher, A. F., \& Meyer, L. L. (1998). Gender and negotiator competitiveness: A meta-analysis. Organizational Behavior and Human Decision Processes, 76, 1-29.

Walther, J. B., \& Parks, M. R. (2002). Cues filtered out, cues filtered in: Computer-mediated communication and relationships. In M. L. Knapp \& J. A. Daly (Eds.), Handbook of interpersonal communication (3rd ed., pp. 529-563). Thousand Oaks, CA: Sage.

Watson, C. (1994a). Gender differences in negotiating behavior and outcomes: Fact or artifact? In A. Taylor \& J. Beinstein-Miller (Eds.), Conflict and gender. Cresskill, NJ: Hampton Press, Inc.

Watson, C. (1994b). Gender versus power as a predictor of negotiation behavior and outcomes. Negotiation Journal (April), 117-127.

Weber, M. (1968). Economy and society (E. Frischoff, Trans.). New York: Bedminister Press. 


\section{Appendix A}

\section{Question 3}

By now you must have received the salary and benefits offer from the company. Is there anything else you would like us to keep in mind as we consider your management placement?

\section{Responses by Condition}

No Ask

Yes, I received the salary and benefits package. The benefits information was very clear. Geographically, I am totally unconstrained. I am happy to work anywhere, as long as I have got interesting stuff to do.

Moderate Ask

Yes, I received the salary and benefits package. The benefits information was very clear. Geographically, I am totally unconstrained. I am happy to work anywhere, as long as I have got interesting stuff to do. What was not clear to me, however, was whether that salary represented the top of the pay range. I understand that there is a range in terms of how much junior managers are paid in their first placement. I would like to be paid at the top of that range. I would also like to be eligible for an end-of-year performance bonus.

Strong Ask

Yes, I received the salary and benefits package. The benefits information was very clear. Geographically, I am totally unconstrained. I am happy to work anywhere, as long as I have got interesting stuff to do. What was not clear to me, however, was whether that salary represented the top of the pay range. I understand that there is a range in terms of how much junior managers are paid in their first placement. I think I should be paid at the top of that range. This is really important to me; I think I deserve it. I also would like to be eligible for an end-of-year bonus. I 
know performance bonuses are not standard for junior managers, but I would certainly be more motivated if I could look forward to a performance bonus at the end of the year. I am thinking of something in the 25 to $50 \%$ of salary range. Not doubling my salary or anything. And, listen, I don't care if it's in cash or stocks - and I promise you I'll earn it. So, those are the two things that I am asking with regard to my compensation: one, paying me at the top of the junior manager salary range and, two, providing me with an end of year, $20-50 \%$ of salary performance bonus. 
Author Note

Hannah Riley Bowles, John F. Kennedy School of Government, Harvard University; Linda Babcock and Lei Lai, H. John Heinz III School of Public Policy and Management, Carnegie Mellon University.

We gratefully acknowledge support from the National Science Foundation SES-0213474 and the Center for Public Leadership at the Kennedy School of Government, Harvard University. The authors would like to thank the following people for their helpful comments on this manuscript: Elaine Backman, Diane Burton, Robin Ely, Frank Flynn, Adam Galinsky, Michele Gelfand, Fiona Greig, Laura Kray, Jennifer Lerner, Kathleen McGinn, Denise Rousseau, Maureen Scully, and William Simpson.

Correspondence concerning this manuscript should be addressed to Hannah Riley Bowles, Kennedy School of Government, 79 JFK Street, Cambridge, Massachusetts, 02138. Email: hannah_bowles@harvard.edu 


\section{Footnotes}

${ }^{1}$ As quoted by Jackman (1994, p. 79), who obtained quote from Myrdal (1994, p. 1074).

${ }^{2}$ We use the term "gender” throughout, because "sex” connotes stable individual differences and we are studying the influence of social situations on men's and women's behavior (Deaux \& LaFrance, 1998).

${ }^{3}$ We ran a second preliminary study using the same basic procedure described in Experiment 1. Participants were 176 adults recruited from the website of a university-based experimental research laboratory. The interview notes in the Ask condition said that the candidate had asked to be paid at the top of the salary range. We observed a significant interaction between Gender of Candidate $\times$ Ask, such that evaluators penalized female candidates more than the male candidates for attempting to negotiate $(F[1,172]=4.62, p<.04)$. There were no significant effects of gender of evaluator ( $p s>.71)$.

${ }^{4}$ Using these criteria, we excluded more than twice as many cases in the ask as in the no ask condition. We suspect that this was due to the phrasing of the manipulation check questions, which tested the participants' memory of what the candidate had asked for during the interview. If participants did not read the full script, then they were more likely to get these questions wrong in the ask vs. no ask condition. There was no other discernable pattern in the cases excluded. Exclusion of these cases had no effect on the results.

${ }^{5}$ For each mediation analysis we also calculated the Aroian and the Goodman tests and report if the results of the tests differ across the three methods (Aroian, 1947; Goodman, 1960).

${ }^{6}$ The website required participants to launch the video before proceeding to the Evaluation Survey, but it did not prevent participants from closing down the video midstream. 
We suspect that these participants did not watch the entire video. The excluded cases appeared to be randomly distributed across conditions, and had no effect on the results.

${ }^{7}$ For the ANOVA presented in Table 6, we tested whether there were actor-specific effects - that is, whether evaluations of the female actors differed from one another and whether the evaluations of the male actors differed from one another. We found no statistically significant differences between the actors of the same gender (all ps $>.14$ ).

${ }^{8}$ There were no gender effects on nervousness or anticipated backlash for the no ask plan (ps $>$.12). To streamline the presentation of results, we do not discuss these variables further.

${ }^{9}$ The excluded cases appeared to be randomly distributed across conditions. Consistent with the premise that they added noise to the analyses, exclusion of these cases increased the statistical significance of the findings, but had no other effect on the overall pattern of results. 
Table 1

Experiment 1: ANOVA of Hireability by Gender of Candidate, Ask Condition and Gender of Evaluator $(N=119)$

\begin{tabular}{lcccc}
\hline \multicolumn{1}{c}{ Source } & df & $M S$ & $F$ & $\eta^{2}$ \\
\hline Gender of Candidate & 1 & 1.19 & 1.02 & .01 \\
Ask & 1 & 34.84 & $29.97^{* * *}$ & .07 \\
Gender of Evaluator & 1 & 0.28 & 0.24 & .002 \\
Gender of Candidate $\times$ Ask & 1 & 5.58 & $4.80^{*}$ & .04 \\
Gender of Candidate $\times$ Gender of Evaluator & 1 & 0.13 & 0.11 & .001 \\
Ask $\times$ Gender of Evaluator & 1 & 0.82 & 0.71 & .01 \\
Gender of Evaluator $\times$ Ask $\times$ Gender of Candidate & 1 & 0.02 & 0.02 & .0001 \\
Error & 111 & & & \\
\hline
\end{tabular}

${ }^{*} p<.05 .{ }^{* * *} p<.001$. 
Table 2

Experiment 1: Means of Hireability by Gender of Candidate and Ask Condition

\begin{tabular}{|c|c|c|c|c|c|}
\hline \multicolumn{3}{|c|}{ Male Candidate } & \multicolumn{3}{|c|}{ Female Candidate } \\
\hline No Ask & Ask & Effect of Ask & No Ask & Ask & Effect of Ask \\
\hline$M$ & $M$ & $d$ & $M$ & $M$ & $d$ \\
\hline $5.94^{\mathrm{a}}$ & $5.26^{\mathrm{b}}$ & 0.65 & $6.19^{\mathrm{a}}$ & $4.63^{c}$ & 1.44 \\
\hline$(0.97)$ & (1.10) & & $(0.86)$ & $(1.26)$ & \\
\hline$n$ & $n$ & & $n$ & $n$ & \\
\hline 26 & 33 & & 29 & 31 & \\
\hline
\end{tabular}

Note: We report standard deviations in parentheses below the means. Different superscripts between ask conditions indicate significant mean differences, ${ }^{\mathrm{a}, \mathrm{b}}$ at the level of $p<.05$ and ${ }^{\mathrm{a}, \mathrm{c}}$ at the level of $p<.001$. 
Table 3

Experiment 2: ANOVA of Willingness to Work with Candidate by Gender of Candidate, Ask Condition and Gender of Evaluator $(N=236)$

\begin{tabular}{lcccc}
\multicolumn{1}{c}{ Source } & $d f$ & $M S$ & $F$ & $\eta^{2}$ \\
\hline Gender of Candidate & 1 & 3.27 & 2.01 & .01 \\
Ask $^{\mathrm{a}}$ & 1 & 26.62 & $16.38^{* * *}$ & .07 \\
Gender of Evaluator & 1 & 3.24 & 1.99 & .01 \\
Gender of Candidate $\times$ Ask & 1 & 10.95 & $6.74^{*}$ & .03 \\
Gender of Candidate $\times$ Gender of Evaluator & 1 & 0.16 & 0.10 & .0004 \\
Ask $\times$ Gender of Evaluator & 1 & 1.53 & 0.94 & .004 \\
Gender of Candidate $\times$ Ask $\times$ Gender of Evaluator & 1 & 1.68 & 1.03 & .01 \\
Error & & & & \\
\hline
\end{tabular}

${ }^{\text {a }}$ Moderate and strong ask conditions combined into one ask condition as compared to no ask condition.

${ }^{*} p<.05 .{ }^{* * *} p<.001$. 
Table 4

Experiment 2: Means of Willingness to Work with Candidate by Gender of Candidate and Ask Condition

\begin{tabular}{|c|c|c|c|c|c|}
\hline \multicolumn{3}{|c|}{ Male Candidate } & \multicolumn{3}{|c|}{ Female Candidate } \\
\hline No Ask & Ask & Effect of Ask & No Ask & Ask & Effect of Ask \\
\hline$M$ & $M$ & $d$ & $M$ & $M$ & $d$ \\
\hline $3.24^{\mathrm{a}}$ & $3.02^{\mathrm{a}}$ & .17 & $3.94^{\mathrm{a}}$ & $2.80^{\mathrm{b}}$ & .95 \\
\hline (1.39) & $(1.24)$ & & $(1.16)$ & $(1.22)$ & \\
\hline$n$ & $n$ & & $n$ & $n$ & \\
\hline 45 & 73 & & 40 & 78 & \\
\hline
\end{tabular}

Note: We report standard deviations in parentheses below the means. Different superscripts $\left({ }^{\mathrm{a}, \mathrm{b}}\right)$ between ask conditions indicate significant mean differences at the level of $p<.001$. 
Table 5

Experiment 2: Means of Potential Mediators, Perceived Niceness and Perceived

Demandingness, by Gender of Candidate and Ask Condition

\begin{tabular}{|c|c|c|c|}
\hline \multicolumn{2}{|c|}{ Male Candidate } & \multicolumn{2}{|c|}{ Female Candidate } \\
\hline No Ask & Ask & No Ask & Ask \\
\hline$M$ & $M$ & $M$ & $M$ \\
\hline \multicolumn{4}{|c|}{ Niceness } \\
\hline $4.14^{\mathrm{a}}$ & $3.54^{\mathrm{b}}$ & $4.55^{\mathrm{a}}$ & $3.62^{b}$ \\
\hline$(0.83)$ & $(0.84)$ & $(0.75)$ & $(0.94)$ \\
\hline \multicolumn{4}{|c|}{ Demandingness } \\
\hline $3.20^{\mathrm{a}}$ & $4.60^{\mathrm{b}}$ & $2.83^{\mathrm{a}}$ & $4.59^{b}$ \\
\hline$(0.96)$ & $(1.07)$ & $(1.05)$ & $(1.33)$ \\
\hline$n$ & $n$ & $n$ & $n$ \\
\hline 45 & 73 & 40 & 78 \\
\hline
\end{tabular}

Note: We report standard deviations in parentheses below the means. Different superscripts $\left({ }^{\mathrm{a}, \mathrm{b}}\right.$ ) between ask conditions indicate significant mean differences at the level of $p<.001$. 
Table 6

Experiment 3: ANOVAs of Willingness to Work with Candidate by Gender of Candidate, Ask Condition and Gender of Evaluator ( $\mathrm{N}=247)$

\begin{tabular}{lcccc}
\multicolumn{1}{c}{ Source } & $d f$ & $M S$ & $F$ & $\eta^{2}$ \\
\hline Gender of Candidate & 1 & 4.17 & 2.51 & .01 \\
Ask & 1 & 57.78 & $34.71^{* * *}$ & .13 \\
Gender of Evaluator & 1 & 0.45 & 0.27 & .001 \\
Gender of Candidate $\times$ Ask & 1 & 0.97 & 0.58 & .002 \\
Gender of Candidate $\times$ Gender of Evaluator & 1 & 0.14 & 0.09 & .0003 \\
Ask $\times$ Gender of Evaluator & 1 & 0.85 & 0.51 & .002 \\
Gender of Candidate $\times$ Ask $\times$ Gender of Evaluator & 1 & 9.67 & $5.81^{*}$ & .02 \\
Error & & & &
\end{tabular}

${ }^{*} p<.05 .{ }^{* * *} p<.001$. 
Table 7

Experiment 3: Means of Willingness to Work with Candidate by Gender of Candidate, Ask Condition and Gender of Evaluator

\begin{tabular}{|c|c|c|c|c|c|c|}
\hline \multirow[b]{3}{*}{ Gender of Evaluator } & \multicolumn{3}{|c|}{ Male Candidate } & \multicolumn{3}{|c|}{ Female Candidate } \\
\hline & No Ask & Ask & Effect of Ask & No Ask & Ask & Effect of Ask \\
\hline & $M$ & $M$ & $d$ & $M$ & $M$ & $d$ \\
\hline \multirow[t]{2}{*}{ Male } & $4.10^{\mathrm{a}}$ & $3.75^{\mathrm{a}}$ & 0.27 & $4.85^{\mathrm{a}}$ & $3.43^{b}$ & 1.14 \\
\hline & (1.07) & (1.53) & & (1.27) & $(1.22)$ & \\
\hline \multirow[t]{3}{*}{ Female } & $4.49^{\mathrm{a}}$ & $3.09^{b}$ & 1.16 & $4.53^{\mathrm{a}}$ & $3.68^{\mathrm{c}}$ & 0.60 \\
\hline & (1.03) & (1.38) & & $(1.48)$ & (1.33) & \\
\hline & $n$ & $n$ & & $n$ & $n$ & \\
\hline Male & 28 & 19 & & 25 & 23 & \\
\hline Female & 41 & 35 & & 38 & 38 & \\
\hline
\end{tabular}

Note: We report standard deviations in parentheses below the means. Different superscripts between ask conditions indicate significant mean differences, ${ }^{\mathrm{a}, \mathrm{b}}$ at the level of $p<.001$ and ${ }^{\mathrm{a}, \mathrm{c}}$ at the level of $p=.01$. 
Table 8

Experiment 3: Means of Potential Mediators, Perceived Niceness, Perceived Demandingness and Competence, by Gender of Candidate, Ask Condition and Gender of Evaluator

\begin{tabular}{|c|c|c|c|c|c|c|c|c|}
\hline \multirow{3}{*}{$\begin{array}{l}\text { Gender of } \\
\text { Evaluator }\end{array}$} & \multicolumn{4}{|c|}{ Male Candidate } & \multicolumn{4}{|c|}{ Female Candidate } \\
\hline & \multicolumn{2}{|c|}{ No Ask } & \multicolumn{2}{|c|}{ Ask } & \multicolumn{2}{|c|}{ No Ask } & \multicolumn{2}{|c|}{ Ask } \\
\hline & $M$ & $S D$ & $M$ & $S D$ & $M$ & $S D$ & $M$ & $S D$ \\
\hline & \multicolumn{8}{|c|}{ Niceness } \\
\hline Male & $4.18^{\mathrm{a}}$ & 0.81 & $3.77^{\mathrm{a}}$ & 1.08 & $4.63^{\mathrm{a}}$ & 1.01 & $3.92^{b}$ & 1.13 \\
\hline \multirow[t]{2}{*}{ Female } & $4.66^{\mathrm{a}}$ & 0.90 & $3.18^{\mathrm{C}}$ & 1.00 & $4.82^{\mathrm{a}}$ & 0.96 & $3.67^{c}$ & 0.91 \\
\hline & \multicolumn{8}{|c|}{ Demandingness } \\
\hline Male & $3.57^{\mathrm{a}}$ & 0.99 & $5.13^{\mathrm{c}}$ & 1.22 & $3.02^{\mathrm{a}}$ & 1.06 & $4.85^{\mathrm{C}}$ & 0.81 \\
\hline \multirow[t]{2}{*}{ Female } & $2.86^{\mathrm{a}}$ & 1.24 & $5.35^{\mathrm{c}}$ & 1.17 & $2.82^{\mathrm{a}}$ & 1.22 & $4.88^{\mathrm{C}}$ & 1.10 \\
\hline & \multicolumn{8}{|c|}{ Competence } \\
\hline Male & $4.17^{\mathrm{a}}$ & 1.17 & $4.44^{\mathrm{a}}$ & 1.25 & $4.83^{\mathrm{a}}$ & 0.93 & $4.54^{\mathrm{a}}$ & 1.17 \\
\hline \multirow[t]{2}{*}{ Female } & $4.54^{\mathrm{a}}$ & 1.22 & $3.82^{b}$ & 1.38 & $4.45^{\mathrm{a}}$ & 1.44 & $4.18^{\mathrm{a}}$ & 1.15 \\
\hline & $n$ & & $n$ & & $n$ & & $n$ & \\
\hline Male & 28 & & 19 & & 25 & & 23 & \\
\hline Female & 41 & & 35 & & 38 & & 38 & \\
\hline
\end{tabular}

Note: Different superscripts between ask conditions indicate significant mean differences, ${ }^{\mathrm{a}, \mathrm{b}}$ at the level of $p<.05$ and ${ }^{\mathrm{a}, \mathrm{c}}$ at the level of $p<.001$. 
Table 9

Experiment 4: ANOVA of Likelihood of Using Ask vs. No Ask Plan ( $\mathrm{N}=341)$

\begin{tabular}{lcccc}
\hline \multicolumn{1}{c}{ Source } & $d f$ & $M S$ & $F$ & $\eta^{2}$ \\
\hline Gender of Participant & 1 & 3.46 & 1.17 & .003 \\
Gender of Evaluator & 1 & 0.06 & 0.02 & .000 \\
Gender of Participant $\times$ Gender of Evaluator & 1 & 12.23 & $4.13^{*}$ & .01 \\
Error & 337 & & & \\
\hline${ }^{*} p<.05$. & & & &
\end{tabular}


Table 10

Experiment 4: Mean Gender Differences in the Likelihood of Using Ask vs. No Ask Plan by Gender of Evaluator

\begin{tabular}{|c|c|c|c|c|c|}
\hline \multicolumn{3}{|c|}{ Male Evaluator } & \multicolumn{3}{|c|}{ Female Evaluator } \\
\hline Male & Female & Gender & Male & Female & Gender \\
\hline Participant & Participant & Difference & Participant & Participant & Difference \\
\hline$M$ & $M$ & $d$ & $M$ & $M$ & $d$ \\
\hline $2.52^{\mathrm{a}}$ & $1.94^{\mathrm{b}}$ & .32 & $2.17^{\mathrm{a}}$ & $2.34^{\mathrm{a}}$ & .10 \\
\hline (1.91) & (1.66) & & (1.64) & (1.64) & \\
\hline$n$ & $n$ & & $n$ & $n$ & \\
\hline 81 & 80 & & 90 & 90 & \\
\hline
\end{tabular}

Note. We report standard deviations in parentheses below the means. Different superscripts $\left({ }^{\mathrm{a}, \mathrm{b}}\right.$ ) indicate significant gender difference within condition at the level of $p<.05$. 
Table 11

Experiment 4: Mean Gender Differences in Nervousness about Using Ask Plan and Anticipated Backlash from Using Ask Plan by Gender of Evaluator

\begin{tabular}{|c|c|c|c|}
\hline \multicolumn{2}{|c|}{ Male Evaluator } & \multicolumn{2}{|c|}{ Female Evaluator } \\
\hline Male Participant & Female Participant & Male Participant & Female Participant \\
\hline$M$ & $M$ & $M$ & $M$ \\
\hline \multicolumn{4}{|c|}{ Nervousness about Using Ask Plan } \\
\hline $5.36^{\mathrm{a}}$ & $5.90^{\mathrm{b}}$ & $5.58^{\mathrm{a}}$ & $5.83^{\mathrm{a}}$ \\
\hline$(1.27)$ & $(1.22)$ & $(1.23)$ & $(1.18)$ \\
\hline \multicolumn{4}{|c|}{ Anticipated Backlash from Using Ask Plan } \\
\hline $4.56^{\mathrm{a}}$ & $4.83^{\mathrm{a}}$ & $5.06^{\mathrm{a}}$ & $4.72^{\mathrm{a}}$ \\
\hline$(1.67)$ & $(1.62)$ & $(1.37)$ & $(1.68)$ \\
\hline$n$ & $n$ & $n$ & $n$ \\
\hline 81 & 80 & 90 & 90 \\
\hline
\end{tabular}

Note. We report standard deviations in parentheses below the means. Different superscripts $\left({ }^{\mathrm{a}, \mathrm{b}}\right.$ ) indicate significant gender difference within condition at the level of $p<.05$. 